expected it to be. Many subscribers are interested in the topic of computer chess but are disappointed in the amount of technical material in the Journal. Essentially they believed it to be more of a chess magazine than a computer magazine.

In conclusion, the ICCA's financial picture looks much brighter than it did in 1986. However, the Journal continues to lose a large amount of money each year. As it currently stands, all ICCA income goes towards subsidizing the Journal and this undermines the association's ability to sponsor new activities. We cannot always expect to have generous sponsors to keep our organization afloat. It is imperative that the Journal becomes more of a break even proposition. The best way for this to happen is to increase the ICCA membership. A doubling of membership would go a long way to solving this problem. The ICCA executive welcome any suggestions on this matter.

\title{
DEEP THOUGHT RECEIVES THE FREDKIN INTERMEDIATE PRIZE
}

\section{The Editorial Board}

Let us recall that Professor Edward Fredkin, of MIT fame, attached three prizes to three yet undreamed-of achievements in computer chess. The first, worth US $\$ 5000$, was for the first computer to attain master status. As is well-known, it was won as for back as 1983 by Ken Thompson and Joe Condon of the BELLE stable (cf. ICCA Journal, Vol. 6 , No. 4, p. 3) The top award, US $\$ 100,000$, is to go to the first computer system to beat the then reigning World Champion in a match.

We all hope to be alive and playing when that prize is awarded, but in most estimates that day is still far off. In between, there is the intermediate prize, worth US $\$ 10,000$. This was to be awarded to the first computer system to maintain a rating above 2500 USCF rating points for 25 consecutive games. Deep Thought has won it by a generous margin, actually achieving 2550 according to Murray Campbell, one of its developers.

Over the Thanksgiving weekend, Deep Thought played in the US \$130,000 Software Toolworks Championship with success as reported in ICCA Journal, Vol. 11, No. 4, pp. 199-200. It was the first time a computer was a cowinner of a tournament with an over US $\$ 100,000$ prize fund, or for that matter, any tournament with GMs playing. (Deep Thought, being a computer, is not eligible to the tournament prizes.) As reported in the previous issue of the ICCA Journal, GM Bent Larsen lost to Deep Thought in the third round to become the first GM to lose to a computer in a regular tournament. Larsen's 2560 FIDE rating made him the highest FIDE-rated player so far to lose to a computer. Deep Thought's 2745 (USCF scale) performance in this tournament is also by far the highest ever for a computer. (In passing, it is noted that the USCF rating is usually inflated by about 70-100 points with respect to FIDE rating. Gary Kasparov, the reigning World Champion, is about FIDE 2760, or about USCF 28302860.) The 6-month old Deep Thought (December 1988) had then played 42 rated games. It played against International Masters 7 times, and won 5, drew 2, no loss. It played International Grandmasters 3 times, and won 1, lost 2 (the loss against GM Lev Alburt was due to a bug that caused the machine to throw away a repetition draw).

As to the where and when of the prize-giving ceremony, this Journal will try to keep you posted or, failing that, at least give you a blow-by-blow account of toasts proposed, speeches made and possibly moves played on that occasion. Let us note that the Award came earlier than many of us expected and that, the world being such as it is, it will not stop the sneering of some whose opinions are frozen into the paradigm that computers can't play chess.

The Deep Thought team includes: Thomas Anantharaman, Mike Browne, Murray Campbell, Feng-hsiung Hsu, and Andreas Nowatzyk, all with the Computer Science Department at Carnegie-Mellon University. They recognize the help and encouragement of many who made this success possible, and particularly mention Lawrence Butcher, Stuart Cracraft, Jim Gillogly, Peter Jansen, Larry Kaufman, Kai-Fu Lee, Tom Mitchel, Raj Reddy, Danny Sleator, Ken Thompson, Hide Tokuda, John Zsarnay and their advisors Roberto Bisiani, Ed Clarke, H.T. Kung and Bob Sproull.

[For much of this news item, the Editors of this Journal have gratefully relied on Email emanating from Fenghsiung Hsu and others as well as on other publications.] 